\title{
Apontamentos teórico-metodológicos sobre a prática de ensino na formação inicial ${ }^{1}$
}

\author{
Theoretical and methodological notes about \\ teaching practices in the beginning of the educational process
}

Ana Lúcia Guedes-Pinto²

Roseli Aparecida Cação Fontana ${ }^{3}$

\begin{abstract}
Resumo
Neste texto, focalizamos nosso processo de elaboração da prática de ensino a partir do lugar em que atuamos: na condição de formadoras de professores das séries iniciais do ensino fundamental. Explicitamos o modo pelo qual temos exercitado a prática de ensino no cotidiano da docência como um projeto pedagógico de formação e seu processo de construção como objeto de investigação. Assumindo a perspectiva de compreensão das práticas culturais cotidianas e a perspectiva da corrente sócio-histórica, problematizamos as opções que temos feito, junto aos nossos alunos - professores em formação, no encaminhamento do trabalho de inserção no cotidiano da escola básica. Tendo como referência a assunção de que cada escola está em um permanente movimento social de construção, temos atuado levando em conta alguns princípios que têm norteado as várias maneiras de nossos alunos inserirem-se nas dinâmicas escolares.
\end{abstract}

Palavras-chave: Prática de Ensino; Formação de Professores; Cultura e Ensino

\section{Abstract}

In the present text we focus our research on the teaching practices starting from our experiences as professionals educating future teachers for elementary school. We expose the method adopted in the tuition practice in the school daily life as an educational project, and choose its construction process as our investigation subject. Adopting a perspective of understanding daily cultural experiences and the social and historical methodology, we debate the options we have next to the students - future teachers trying to insert them in the reality of elementary school. Believing that each school is in a permanent social transformation, we have been working considering some principles guiding the several forms present in the insertion process of the students in the elementary school.

Keywords: Teaching Practices; Teacher's Education; Culture and Tuition

\footnotetext{
O teor desse texto foi apresentado no GT (Grupo de Trabalho) "Formação de Professores" da ANPEd em 2005.

2 Professora da Faculdade de Educação da Unicamp (Campinas/Brasil) e Pesquisadora do Grupo AULA - Trabalho Docente na Formação Inicial. alguedes@mpc.com.br.

3 Professora da Faculdade de Educação da Unicamp (Campinas/Brasil) e Pesquisadora do Grupo AULA - Trabalho Docente na Formação Inicial. roap@uol.com.br.
} 


\section{INTRODUÇÃO}

A prática de ensino nos cursos de formação inicial vem ganhando destaque, nos últimos anos, entre nós, educadores, tanto em função das reformulações curriculares desencadeadas pela implementação da nova LDB, quanto em função de preocupações epistemológicas, derivadas dos chamados "saberes da prática", presentes, segundo Chartier e JacquetFrancillon (1998), em todas as ciências humanas, a partir dos anos 1960.

O retorno das práticas (sociais, culturais, profissionais, cognitivas) ao coração do debate intelectual, de acordo com esses autores, resultou da conjunção de três grandes embates: a discussão das relações entre cultura e sociedade, impulsionada pelos movimentos anticolonialistas, pelas reivindicações regionalistas e pelas inquietações suscitadas pelos impactos da cultura de massas e sua internacionalização; as mutações no mundo do trabalho, que deslocaram o saber-fazer, transmitido no exercício do próprio trabalho, em favor da racionalização e planificação das cadeias produtivas; e as "incertezas" decorrentes de um sistema escolar em crise, denunciado, em sua lógica excludente, pelas contradições do fracasso escolar.

Essas condições históricas trouxeram, para o interior da formação, a discussão da diversidade cultural e dos saberes da prática, entendidos como saberes não escolares, que haviam sido constrangidos pela hegemonia dos saberes científicos e laicos da escola republicana, "instituídos como os saberes da modernidade crítica e emancipatória" (op. cit., p. 6). Entretecidos às discussões pedagógicas, os chamados "saberes da prática" passaram a compor as pautas das políticas públicas e as propostas curriculares.

Envolvidas, desde meados dos anos 1990, com as disciplinas teóricopráticas ${ }^{4}$ específicas da formação dos futuros professores no curso de Pedagogia de nossa universidade, temos vivido as questões relativas aos processos de apropriação e de elaboração das práticas docentes na formação inicial, tanto do ponto de vista do trabalho por nós desenvolvido

4 São elas: Didática, Metodologia de Ensino, Prática de Ensino nas Séries Iniciais do Ensino Fundamental e Estágio Supervisionado. 
como professoras-formadoras, quanto do ponto de vista da teorização e da construção dessa temática como objeto de estudo e de investigação, no interior do Grupo de pesquisa a que pertencemos. Nesse grupo, juntamente com nossos orientandos de graduação, de pós-graduação e professores do Ensino Fundamental vinculados aos grupos de estudo por nós coordenados, tematizamos o trabalho docente na formação inicial. ${ }^{5}$

Os exercícios de sistematização das reflexões suscitadas por nossas ações docentes e das referências que as têm subsidiado, os esforços de teorização e o estabelecimento dos princípios metodológicos desse trabalho têm sido por nós documentados, analisados e divulgados desde 2000. Nesses trabalhos anteriores, enfocamos o processo vivido com nossos alunos acerca de suas inserções na escola básica e o modo como fomos apreendendo as relações sociais produzidas entre os sujeitos que fazem a escola e são por ela constituídos.

No texto, ora apresentado, pretendemos focalizar nosso processo de elaboração da prática de ensino, explicitando como a exercitamos no cotidiano da docência como projeto pedagógico de formação e seu processo de construção como objeto de investigação no curso de nossa atividade como professoras. Assumindo a perspectiva de compreensão das práticas culturais cotidianas apresentada por Certeau (1994) e também tematizada por Bakhtin (1986) e Vygotsky $(1984,1987)$ ao longo de suas produções, tomamos como foco as relações sociais vividas pelos sujeitos ordinários, anônimos, buscando compreender seus atos singulares e os processos de sua realização, de suas operações. Assim, procuramos, através dos indícios deixados por aqueles que vivem o cotidiano escolar, entender o processo de apropriação e reinvenção de suas práticas e, também por meio deles - os vestígios -, encontrar alguns indicativos para o processo de formação protagonizado pelos nossos estudantes de Pedagogia.

Finalmente, pretendemos também trazer alguma contribuição para a perspectiva dos estudos sobre a formação inicial tomando a reflexão sobre a nossa prática pedagógica de professoras formadoras de futuros professores. Segundo investigação de Brzezinski e Garrido (2001, p. 95) sobre a produção científica apresentada no Grupo de Trabalho "Formação de Professores" da ANPEd (Associação Nacional de Pós-Graduação e

5 Mantemos dois grupos de estudo com professores das séries iniciais e com nossos orientandos de graduação e pós-graduação nos quais estudamos as práticas escolares, as relações de ensino vividas nas escolas e o processo de ser e estar sendo professor. 
Pesquisa em Educação) no período de 1992 a 1998, não houve presença de trabalhos que tenham problematizado o processo de ensino vivido por aqueles que formam os futuros professores. As autoras afirmam: "Os professores foram estudados pelos formadores-pesquisadores. Não foi analisado o formador do professor." Assim, procuramos inserir este trabalho na linha de estudos sobre o formador de professor.

\section{A FORMAÇÃo COMO INTERVENÇÃo históRICA}

Hébrard (2000), em entrevista concedida à revista Presença Pedagógica, assinala que, por passarmos ao largo das determinações históricas da docência e da escola, temos reduzido a formação de professores a um discurso moral, assentado em prescrições relativas aos modos de ação docente, que são, por sua vez, derivadas das concepções pedagógicas em circulação.

No entanto, prossegue ele, para estar na escola, para atuar dentro dela e para modificá-la não bastam prescrições, concepções pedagógicas ou a boa vontade de quem quer que seja, uma vez que nela funcionam, como em qualquer outra atividade humana, complexos dispositivos, produzidos historicamente, cujo funcionamento é necessário conhecer.

Os dispositivos, entendidos como conjuntos organizados e estabilizados de procedimentos relativos às diversas formas de atividade humana, apesar de produzidos em condições históricas determinadas, naturalizam-se como modos de agir, de pensar, de enunciar, aos quais recorremos sem mesmo nos darmos conta. Essa naturalização impõe a necessidade de conhecê-los, o que só a análise histórica possibilita.

Vivemos uma escola assentada no ensino coletivo e simultâneo, na qual os saberes, conforme análise de Chartier e Jacquet-Francillon (1998, p. 6), são "saberes da escrita, em que os livros objetivam materialmente a realidade e a permanência: eles são portadores de referências que são na sua maior parte compostas na forma de textos, mas também se apresentam na forma de imagens, mapas, esquemas, figuras".

Esses saberes, cuja transmissão é considerada necessária por distintas instâncias de controle social (ontem a Igreja, hoje o Estado), são organizados em disciplinas autônomas, transmitidas e avaliadas por profissionais legitimados para sua instrução, que as apresentam de modo formal, linear-progressivo, desvinculando os conhecimentos de seus usos sociais. A exposição dos alunos ao conhecimento organiza-se em um tempo 
que segue um ritmo normatizado e regularizado por uma cadência que procura distribuir-se de forma homogênea. O tempo, sob esse aspecto, é marcado de maneira compassada pelos exercícios e tarefas que ocupam o fazer de alunos e professores.

Comênius, já no século XVII, com a escrita da Didática magna, ao buscar a implementação do ensino sistematizado e que pudesse atender coletivamente as comunidades então excluídas do acesso ao conhecimento do ler e escrever, estabelece o uso organizado do tempo e do espaço como uma questão vital para a consolidação do projeto de uma escola para todos. Para que o ensino pudesse ser acessível a uma maioria e que atendesse às necessidades da aprendizagem da língua e dos rudimentos das operações aritméticas, Comênius defendia uma organização do trabalho pedagógico que permitisse aos professores gerir em um mesmo tempo e espaço o ensino daqueles conhecimentos que se almejava de domínio público.

Para que se difundisse esse ensino, na perspectiva defendida, via-se como uma demanda emergente a sistematização de uma série de saberes relativos ao ensinar, fundando-se assim uma certa prática especificamente escolar. Essas práticas envolviam uma organização do espaço da sala de aula de modo a adequar-se à acomodação dos alunos e favorecer ao professor formas de acesso e de controle aos seus corpos - gestos, movimentos, atenção - e das tarefas realizadas, permitindo que, em um tempo determinado, os exercícios pudessem ser copiados, corrigidos e refeitos. ${ }^{6}$

O tempo das práticas escolares organizadas segundo essa série de dispositivos sistematizados por Comênius, e que até os dias de hoje vigoram, compõem, segundo Hébrard, o tempo das práticas, que é muito lento, quase imutável. No entanto, a lentidão do tempo das práticas não significa imobilismo, uma vez que essas práticas, como todas as práticas sociais, ganham nuances e redimensionamentos ao longo do decurso da história, em função dos usos, que delas vão sendo feitos, em contextos específicos. Nesse sentido, como destaca Hébrard, "a intervenção na educação,

6 Com relação aos efeitos e desdobramentos do uso do controle do espaço escolar e à questão da disciplina do corpo instaurada por essa organização da instituição educacional, Foucault desenvolveu diversos estudos como Vigiar e punir e Microfísica do poder, enfatizando os aspectos da coerção e dominação dos sujeitos nesse tipo de ambiente. Não é nosso objetivo neste artigo nos deter sobre essa perspectiva de análise da escola. 
particularmente na formação, não é uma intervenção que se faz com objetivo pedagógico, é uma intervenção que se faz dentro da determinação da própria história” (2000, p. 7, grifos nossos), o que implica assumir que tanto as práticas escolares quanto a elaboração do conhecimento sobre elas não se produzem de forma abstrata.

Tendo esses princípios em conta, Hébrard (op. cit., p. 7) enfatiza a descrição da escola como uma forma de intervenção: "Se você é capaz de descrever bem o que acontece na escola, o que é a escola, você é capaz de mudá-la um pouquinho."

Se tomarmos essa perspectiva como um pressuposto de trabalho na formação de professores, nos perguntamos: Como ensinar nossos alunos a descrever a escola?

\section{Descrever - significados e possibiLidades}

A descrição, segundo os dicionários, consiste em uma exposição circunstanciada, feita em palavras, a respeito de algo, alguém ou de um acontecimento. Ou seja, consiste em contar minuciosamente a situação, estado ou condição desse algo, desse alguém ou desse acontecimento, em determinado momento.

Mas também há um segundo significado que relaciona o ato de descrever ao movimento, ao traço que se inscreve em um determinado contexto que se segue percorrendo.

Enquanto no primeiro significado destaca-se o dizer sobre aquilo que se descreve, no segundo a ênfase recai no movimento que se inscreve em e, porque se inscreve, marca, deixa indícios no contexto e naquele que o percorre.

Os dois significados pontuam possibilidades de ensino e de aprendizado distintos e não excludentes entre si. A descrição centrada no "dizer sobre" ancora-se naquilo que se apreende pelo olhar e pela escuta. A descrição centrada no movimento implica inserção no contexto, ação, atuação, deslocamento - o seguir percorrendo - no espaço por ele configurado.

Considerando-se que as práticas escolares constituem-se em processos marcados pela alteridade: o ensino, a aula, os exercícios, os diversos dispositivos de controle do espaço e do tempo existentes na dinâmica escolar, tudo iso materializa-se nas relações cotidianas entre os 
sujeitos que vivem a escola, as possibilidades de descrição dessas práticas assentam-se na descrição de relações sociais.

Assim, no caso do primeiro significado de descrição, a descrição da escola desenvolve-se a partir do olhar voltado para a dinâmica relacional produzida entre os sujeitos da escola, em sua coreografia, e da escuta dos enunciados desses sujeitos na dinâmica interlocutiva que se tece entre eles. No segundo caso, a descrição refere-se à da trajetória que os futuros professores inscrevem na escola, focalizando sua inserção nas relações sociais ali produzidas, sua atuação dentro delas, os usos e sentidos nelas materializados e apreendidos e ainda os efeitos dessas relações sobre seus modos de agir, apreender, elaborar e enunciar o outro e a si mesmo.

As duas concepções de descrição abrem possibilidades epistemológicas combináveis no trabalho de formação. O conhecimento sobre as relações que fazem a escola (Como o outro vive as determinações históricas? Que usos faz dos dispositivos que regem a escola? Que significados e sentidos circulam nas relações?) e o conhecimento com os sujeitos que fazem a escola, experimentando-se com eles nos usos desses dispositivos. Assim, no movimento da inserção de nossos alunos na escola básica, indagamos a eles e a nós mesmas: Como olhamos para as relações intersubjetivas que fazem a escola? Como escutamos o que se enuncia e o que se silencia nessas relações? Como participamos dessas relações?

Nesse movimento, destacamos três instâncias de aprendizado das práticas: o olhar; a escuta e a inserção nas relações - a "atuação com".

\section{O OLhar}

Longe de supor a naturalidade da percepção, assumimos que se ensina e se aprende a olhar. A cultura transforma, segundo Vygotsky (1987), a percepção orgânica do homem em percepção de significados. Ou seja, tudo aquilo a que dirigimos nosso olhar é modulado, atravessado, pelo modo cultural de visualizá-lo, instaurado e mediado pelos esquemas conceituais a que temos acesso ao longo de nossa hominização e humanização. Nesse sentido, Bakhtin (1986) afirma que os signos não apenas refletem a realidade, mas a refratam.

Os conceitos historicamente produzidos são apropriados e elaborados, de modo assistemático, na vida, no trabalho, compondo o que Vygotsky denomina como "conceitos espontâneos" e Bakhtin como "ideologia do cotidiano". Parte dos conceitos é organizada em sistemas 
de concepções científicas, filosóficas, morais, jurídicas etc. e são apropriados e elaborados, de modo sistemático e deliberado, em nosso itinerário acadêmico, através das disciplinas formadoras.

Dada a função social da escolarização na modernidade, qual seja a de possibilitar o acesso a sistemas explicativos globais derivados das ciências, a formação privilegia a apropriação dos conceitos sistematizados e a aproximação do real por eles mediada. Nesse sentido, cabe dizer que, no processo de formação, a escola e as relações sociais ali produzidas são apreendidas por um olhar mediado, modulado, sensibilizado pelas teorias (pedagógicas, sociais, históricas, antropológicas, psicológicas etc.), nele disponibilizadas e que funcionam como o prisma privilegiado, através do qual a realidade apreendida é refratada.

No entanto, os sistemas conceituais das disciplinas formadoras, como construções históricas que são, não se realizam como universais, neutros, nem abstratos. Eles são a expressão legitimada e hegemônica de certas práticas de conhecimento e estabelecem as condições dentro das quais a variabilidade de sentidos (historicamente possíveis) pode ser expressa, articulada e validada.

Conforme destaca Ginzburg (1989), em uma análise histórica, muitos dos sistemas conceituais das ciências modernas são calcados na supremacia do paradigma galileano, de orientação quantitativa e antiantropocêntrica.

Esse paradigma, orientado para as regularidades da natureza e para sua explicação na forma de leis universais, assenta-se sobre a crença na transparência da realidade, na separação entre sujeito e objeto e na exclusividade do conhecimento sistemático e formal, abafando, em sua hegemonia, práticas cognoscitivas de raízes antigas na constituição do humano, como o pensamento conjetural.

No caçador agachado na lama, que escruta as pistas da presa, Ginzburg (op. cit., p. 154) "entrevê o gesto mais antigo da história intelectual do gênero humano". Segundo ele, "o caçador teria sido o primeiro a narrar uma história porque era o único capaz de ler, nas pistas mudas, deixadas pela presa, uma série coerente de eventos" (op. cit., p. 152), caracterizando dessa forma o conhecimento conjetural que infere, a partir dos efeitos de ações já acontecidas, mas não observáveis, uma série de informações, tanto no sentido do que se passou (como suas causas, o desenrolar possível daquelas ações), quanto no sentido das possibilidades de seu desenvolvimento futuro (os rumos da presa, por exemplo). 
Profundamente ligado ao concreto e seu caráter individualizante e à possibilidade do conhecimento indireto, o pensamento conjetural opera em uma lógica coordenativa, em que os indícios possibilitam configurar e re-configurar hipóteses por estabelecer elos coerentes entre eventos. $\mathrm{Ou}$ seja, o saber conjetural significa a singularidade dos indícios, das pistas disponíveis, não como um conhecimento isolado, mas na sua interconexão com outros eventos, que vai sendo tecida narrativamente. Dessa forma, o singular é mantido sem que se abandone a idéia de totalidade, de complexidade, e a possibilidade de apreensão daquilo que é imediatamente invisível ao sentido natural de quem vê. Esse modo de conhecer, definido por Ginzburg como paradigma semiótico ou indiciário, negando a transparência da realidade, assume a possibilidade de compreendê-la em seus indícios.

Ao trazer para o debate e para a crítica da ciência moderna o saber conjetural, Ginzburg tematiza a clássica cisão entre teoria e prática. $\mathrm{O}$ saber conjetural, que pode ser reconhecido nas diversas esferas de atividade da vida cotidiana, foi mantido implícito, na história do pensamento ocidental, desde o classicismo grego, que o considerava como uma forma de conhecimento menor, "uma inteligência da prática" (DEJOURS, 1999), relacionada às atividades técnicas, em particular às atividades de fabricação.

Tematizada pelos gregos com o nome de métis, origem etimológica da palavra métier - ofício -, essa forma de inteligência, de acordo com Detienne e Vernant (1974), caracteriza-se por enraizar-se no corpo, nas percepções e intuições sensíveis, e nas exigências da tarefa, sendo mobilizada frente a situações inéditas, ao imprevisto. Marcada pela inventividade e criatividade e por privilegiar a habilidade em detrimento do emprego da força, essa forma de inteligência, segundo Dejours, colocase em constante ruptura com as normas e regras, na medida em que é acionada diante dos problemas concretos encontrados pelos sujeitos em seu confronto com o mundo real e não só com as explicações formuladas por filósofos e cientistas.

Essa inteligência prática é apreensível nos gestos, nos dizeres, nas entonações expressivas e nas ações dos sujeitos. Ela deixa indícios nos modos como esses sujeitos participam das relações que compartilham com seus outros no espaço do trabalho. Como apreendê-las é o desafio que se coloca. 
Valorizando o singular como uma possibilidade de compreender o real em sua opacidade e complexidade, o paradigma indiciário, como destaca Ginzburg, põe em questão o "como" olhar. É neste "como" que reside a diferença entre captar ou não indícios de um saber-fazer em práticas tão marcadas pela repetição e pela aparente homogeneidade como o são as ações escolares.

Como ensinar e aprender esse "como olhar"?

Olhando, vendo, reparando. Ou seja, experimentando-se na visada de um mesmo acontecimento a partir de diferentes pontos de vista e também mediados pela Arte. A literatura, o cinema, o teatro, as imagens, como depositários das infindáveis narrativas do vivido e do imaginado, colocam-nos diante do acontecimento humano, em sua complexidade, singularidade e diversidade, possibilitando-nos a experiência da empatia, da recusa, da identificação, da diferença, entre outras, e o exercício de ver de novo, de buscar o ainda não visto, nos detalhes, nos pormenores considerados negligenciáveis à primeira vista.

Acreditamos também que a construção desse "como olhar" está perpassada pela assunção de que os usos e operações (CERTEAU, 1994) dos sujeitos no tempo/espaço das escolas são pistas importantes sobre as práticas escolares cotidianas e se revelam em detalhes e pormenores das situações. O modo como esses sujeitos - alunos, professores, funcionários, diretores, coordenadores - se apropriam daquilo que lhes é oferecido de forma pronta, como, por exemplo, a organização desse tempo/espaço especificamente escolar, entrevisto em gestos, acordos e redimensionamentos sutis, pode indicar-nos alguns sentidos conferidos por eles à instituição e ao ensino.

Mas o olhar não é suficiente. Como se alcançar apenas pelo olhar o significado das relações sociais (OLIVEIRA, 1994), sem conhecermos as palavras com que os sujeitos se enunciam e enunciam o vivido, sem ouvirlhes a entonação expressiva?

\section{A ESCUTA}

A escuta do outro nos auxilia - a nós e aos nossos alunos - na aproximação do entendimento das ações e operações dos muitos sujeitos que fazem a escola, na medida em que ela possibilita exercitarmos a sensibilidade de nossos ouvidos às vozes e às histórias narradas por esses sujeitos. 
Assim como o olhar, a escuta também é culturalmente modulada. Sua seletividade é marcada pelos paradigmas das disciplinas em que vamos sendo formados. E, nesse sentido, o modo como a relação com o outro é considerada nesses paradigmas faz toda a diferença na situação de escuta.

A tradição galileana nas Ciências Humanas consolidou as relações com o outro como relações sujeito/objeto - pesquisador/informante. Conforme destaque de Oliveira (1994, p. 12):

No ato de ouvir o informante, o [pesquisador] exerce um poder extraordinário sobre o mesmo, ainda que ele pretenda se posicionar como sendo o observador mais neutro possível, como pretende o objetivismo mais radical. Esse poder, subjacente às relações humanas - que autores como Foucault jamais se cansaram de denunciar -, já na relação pesquisador/informante vai desempenhar uma função profundamente empobrecedora do ato cognitivo: as perguntas feitas em busca de respostas pontuais lado a lado da autoridade de quem as faz (com ou sem autoritarismo), criam um campo ilusório de interação.

Campo ilusório por acreditar ser possível a neutralidade idealizada pelos defensores da objetividade absoluta. Ilusão essa que apaga o fato de que a pergunta, quando considerado o jogo de poder constitutivo da relação pesquisador/informante, já contém a resposta, seja ela qual for, tanto pela imagem que o informante tem do pesquisador e de seus interesses, quanto da imagem que o pesquisador tem do informante e seus saberes.

Amado (1995) chama a atenção para o aspecto simbólico que pode estar contido nas narrativas de nossos interlocutores e o quanto precisamos desenvolver certa astúcia para não desprezarmos esses enredos. Também Portelli (1997) destaca a importância de tomarmos as vozes e dizeres do outro como uma possível versão dos fatos vividos. Atribuir e reconhecer seu valor como uma versão pode ser vital para chegarmos aos sentidos conferidos às práticas vividas por cada sujeito, pois, segundo ele, o que importa para chegar a uma compreensão do outro é apreendermos os significados da experiência vivida por esse outro que ouvimos e com o qual interagimos.

A questão das imagens que os sujeitos em interlocução projetam de si e do outro remete à consideração das condições sociais de produção das relações que se produzem entre eles, explicitando o entrelaçamento entre a instância histórica e a dimensão política da formação. Ou seja, os 
enunciados a que temos acesso produzem-se em relações historicamente determinadas, em que se configuram lugares sociais distintos, em termos de poder, de legitimação e valor simbólico, a partir dos quais os sujeitos apreendem os significados postos em circulação, significam os outros com quem interagem e a si mesmos, reafirmando e também re-interpretando os sentidos postos e/ou prescritos. Nesse sentido, a alteridade é constitutiva das enunciações. Todo enunciado é plural porque é o sujeito em relação com seus outros que nele fala.

Bakhtin (1986) conceitua como polifonia essa pluralidade dos enunciados. Um enunciado não significa em si mesmo, mas nas suas relações com enunciados que o precederam e com enunciados que se seguirão a ele. Nesse sentido, cada enunciado é um elo na corrente da comunicação verbal e compõe-se de muitas vozes que remetem a essa complexa trama enunciativa de que faz parte. O vínculo de cada enunciado à corrente da comunicação verbal coloca o contexto da enunciação no interior do próprio enunciado. Ou seja, o extraverbal não é a causa exterior do enunciado e sim um constituinte necessário do próprio enunciado.

A presença das muitas vozes em cada enunciado - presença de um outro discurso no interior do discurso - permite examinar a questão da alteridade na materialidade mesma dos enunciados. $\mathrm{E}$ a análise, nesse caso, refere-se ao modo como aquele que enuncia, no interior das condições específicas de produção de seu enunciado, apropria-se das vozes dos outros e com elas compõe sua "própria" voz.

Assumir a polifonia implica aprender a nos desligarmos da predominância do conteúdo dos enunciados sobre seu estilo, suas entonações, os gestos que os acompanham e a cena em que se inscrevem. Nas Ciências Humanas, é freqüente que o conteúdo ocupe um lugar absoluto, sendo tratado com técnicas mais elaboradas e procedimentos analíticos consolidados (AMORIM, 2001).

A crítica à predominância do conteúdo não significa dizer que ele não é importante, mas que há outras formas de ouvi-lo e de considerá-lo. E, nesse aspecto, também Certeau (2002) tem nos ajudado com algumas pistas no encaminhamento do trabalho.

Ao refletir sobre o processo de escrita da história, ressaltando a importância de se ter em conta as marcas advindas do lugar social do historiador no seu fazer historiográfico e o discurso que articula sobre o outro, Certeau (op. cit., p. 55) adverte a respeito da necessidade de termos em vista as marcas que se entrecruzam na tecedura dos sentidos 
produzidos: "Com efeito, a ciência histórica não pode desligar, inteiramente, a sua prática daquilo que escolheu como objeto, e tem como tarefa indefinida tornar precisos os modos sucessivos dessa articulação."

Temos procurado manter em nosso horizonte essa articulação que se refaz constantemente entre os lugares sociais de onde os sujeitos falam e agem e os vários sentidos que se fabricam nesse cruzamento.

Mas como ensinar/aprender esse modo de escuta?

Bourdieu (1999) define essa forma de escuta como pôr-se em disponibilidade à singularidade da história particular dos sujeitos, tentando afastar a indiferença da atenção, favorecida pela ilusão do já visto e já ouvido.

Como ensinar/aprender esse modo de escuta?

Para essa escuta não há procedimentos estáveis, nem manuais que indiquem a postura e as perguntas corretas. Lins (2004), comentando o método de Eduardo Coutinho ao filmar, assinala que essa forma de escuta se constrói sob o risco do real, em meio a equívocos e, entre acertos e erros, o que parece mostrar-se mais favorável à aproximação com o outro é a escuta que se volta para as narrativas - em que o sujeito aborda suas experiências de vida -, mais do que para as opiniões; uma escuta que busca, na experiência narrada, os indícios de como os sujeitos entendem e definem a vida que levam, seu trabalho, a escola.

Olhar e escuta, assim problematizados, davam-nos a possibilidade do conhecimento sobre a escola, aproximando nossos alunos das práticas e das relações em que elas se desenvolviam. Faltava-nos o conhecimento na escola, produzido pela imersão do futuro professor nas práticas e nas relações vividas na escola.

\section{A INSERÇÃo nAs RELAÇÕes - A ATUAÇÃo COM}

A inserção em um contexto, do mesmo modo que o olhar e a escuta, não é algo natural, ainda que costume ser naturalizado. Como encontrar o outro, aproximar-se dele, compartilhar situações e atividades com ele? Como intervir em seus modos de atuação e na elaboração de suas vivências? Como viver suas intervenções sobre nossos gestos, ações e dizeres?

Essas perguntas, aparentemente corriqueiras, por fazerem parte das experiências de vida de cada um de nós, ganham outra dimensão quando se considera que o encontro com o outro se faz sempre no interior de 
construções e dispositivos - cujo conjunto inserimos no que vimos denominando por condições sociais de produção - que interferem e produzem efeitos de sentido nos sujeitos envolvidos e na dinâmica relacional que se tece entre eles.

Essas condições de produção do encontro com o outro, demarcadas por lugares sociais, caracterizam-se pela dissimetria e pela impossibilidade de fusão entre os sujeitos envolvidos, de forma que não há como viver o lugar do outro, mas compreendê-lo.

Em situações como as dos estágios, em que se trata de inserir-se deliberada e explicitamente em um certo contexto, a consideração do encontro com o outro e seus limites tornam-se explícitos antes mesmo que a relação se instaure.

No tocante a esse aspecto, Augé (1994) auxiliou-nos na teorização do lugar social ocupado pelos futuros professores (estagiários) nas relações escolares, caracterizando-o, como um não-lugar, ou seja, uma posição e um modo de participação nas relações sociais produzidas na escola que se caracteriza pela ausência de vínculos e pelo efêmero, pela provisoriedade de uma condição que, ainda que prolongada, é de passagem. Os estagiários não são alunos da escola onde estagiam, nem tampouco professores, diretores ou funcionários dessa escola, nem alguém ligado às famílias dos alunos que ali estudam, ou à comunidade em que ela se insere. Eles estão "de passagem" pela escola e não têm um lugar assegurado nas relações ali produzidas.

Como não existe um lugar assegurado, o desafio é produzir algum lugar nas relações escolares, vivendo-as. Trata-se da produção de acontecimentos que não preexistem à presença do futuro professor na escola, nem às relações que vai viver ali.

Nesse sentido, não há um roteiro predefinido para a abordagem da escola e para a inserção dentro dela, o que não quer dizer que a presença do estagiário ali não se sustente em princípios, não tenha limites. Antes de tudo, ela não é espontânea. O jovem futuro professor chega à escola em cumprimento a uma tarefa escolar. Sua ida à escola foi precedida e é acompanhada por leituras, conversas, negociações - com a professora da disciplina na Universidade e com as pessoas que vivem o cotidiano da escola. Ele sabe que se espera dele a aproximação desses sujeitos, a escuta atenta, o respeito a seus espaços e práticas. O que não sabe de antemão é o que vai acontecer estando na escola, face a face com os sujeitos singulares 
que a produzem. É nessa relação que vai se construir uma história entre sujeitos, cujo desfecho não se pode antecipar.

No entanto, como a escola é um contexto bastante familiar aos futuros professores, ela fez parte de suas vidas por no mínimo onze anos, eles tendem a lê-la com base no já visto, no já explicado sobre ela e nas prescrições dos projetos de formação, que indicam como atuar dentro dela e transformá-la. Acreditando que já conhecem a escola, seu primeiro impulso, sob a influência desses discursos formadores, é criticá-la em seu funcionamento e projetar modos de ação para corrigir seus rumos, atendose a princípios e objetivos pedagógicos que não se enraízam na vivência dos dispositivos escolares. Nesse movimento, imersos na familiaridade do cotidiano em que se inserem, acabam cegos ao que existe e afastam-se do outro.

No intuito de rompermos com esse modo de inserção, que privilegia o reconhecimento da face institucional e estável da escola, passamos a propor aos estagiários um deslocamento de foco: ao invés de olharem para os professores em atuação e criticarem seus dizeres, gestos e procedimentos, solicitamos que se experimentem no lugar da docência. Como esse lugar não está assegurado a eles na condição de estagiários, explicita-se a necessidade de negociação com os sujeitos que vivem a escola para a produção de um lugar nas relações de ensino.

Desse modo, duas das condições da apropriação e da elaboração dos sentidos das práticas de ensino dão-se a ver: o inscrever-se no contexto de uma escola singular e o experimentar-se na docência, mediado pela relação com o outro que já vive a escola, pela exposição a ele e à diversidade de modos de compreender e fazer a escola que existem no seu cotidiano.

Nessa proposta, mais do que o mero exercício de regência a ser avaliado pelo formador, está em jogo a trajetória que o futuro professor descreve na escola, pela vivência dos dispositivos que a constituem, pela intervenção que neles experimenta e pela análise dos efeitos, limites e possibilidades, dessa intervenção, na dinâmica das relações escolares.

O foco da inserção na escola não é a análise do professor em atuação, nem a auto-análise do estagiário, em uma perspectiva reflexiva, mas o evento, o acontecimento do encontro e confronto entre eles, em um espaço semântico partilhado, do qual cada um participa e (com o qual) opera, a partir dos lugares sociais que ocupa, mantendo a tensão constitutiva dos significados e sentidos produzidos e em disputa acerca do que é a educação escolar e de como realizá-la. 
Do caráter imprevisível dessa trajetória, não se deduz que os métodos e projetos sejam inúteis. Conforme Amorim (2001), eles servem como lugar em que se explicita o modo como o outro é representado e servem para indicar, na medida em que fracassam, o quanto o olhar, a escuta e os modos de ação do futuro professor e dos professores em atuação na escola de Ensino Fundamental e na Universidade comportam pontos cegos em suas explicações e crenças.

Entre os pontos cegos que o fracasso dos projetos possibilita, está a destituição da explicação de que a diversidade de sentidos das práticas escolares, apreendida entre esses professores em confronto, se explica apenas em função da predominância da experiência oriunda do fazer, entre aqueles que atuam na escola básica, e da predominância da formalização (sistematização) entre os futuros professores e os formadores.

Os encontros e confrontos documentados ${ }^{7}$ entre esses professores apontam que a diversidade de sentidos das práticas escolares é também marcada e modulada pelas posições e modos de participação desses sujeitos nas relações sociais por eles compartilhadas, remetendo à análise de suas condições sociais de produção, condições essas que colocam em questão, no que concerne aos formadores, suas concepções acerca dos modos pelos quais a profissão docente é apropriada e elaborada pelos professores em atuação e em formação, remetendo à indagação de como esses processos têm sido por eles possibilitados aos futuros professores.

\section{Considerações finais - as disciplinas teórico-práticas como POSSIBILIDADE DE ENCONTRO COM O OUTRO}

Discutindo o modo como fomos construindo a prática de ensino como projeto pedagógico e objeto de conhecimento, procuramos mostrar de que forma, desde o início de nosso trabalho com as disciplinas de caráter teóricoprático, compreendemos que sua contribuição para a formação advinha das possibilidades, por elas instauradas, de encontro e confronto entre os professores em atuação nas escolas de Ensino Fundamental, os futuros professores em formação e nós, os professores da Universidade. Encontros e confrontos nos quais poderia ganhar visibilidade a diversidade de sentidos de que as práticas escolares se revestem e a importância de se analisar essa diversidade em suas condições sociais de produção.

7 Documentados de várias maneiras, tais como: relatórios escritos sobre a experiência de estágio, os debates em aulas em função dos relatos orais sobre as idas às escolas, os materiais produzidos em conjunto com os sujeitos da escolas. 
Com base nessas possibilidades, definimos como nosso objetivo, nessas disciplinas, a compreensão dos modos de organização do trabalho docente em suas condições sociais de produção, entendendo por organização do trabalho pedagógico a divisão do trabalho na escola, que envolve tanto o conteúdo das tarefas, quanto as relações de poder marcadas pelo sistema hierárquico, pelas modalidades de comando e pela atribuição de responsabilidades, como também os mecanismos estabilizados, nas formas de práticas e significados, que põem em funcionamento o dispositivo escolar. Entendemos, também, que a divisão do trabalho na escola não nasce no seu interior; ela é uma configuração marcada e modulada pela divisão social do trabalho e por suas transformações.

Por compreensão, assumimos a concepção semiótica de Bakhtin (1986), segundo a qual, a compreensão refere-se ao processo de produção de sentidos que acompanha as ações e enunciados (entendidos aqui como ações pela/na linguagem), em que os sujeitos envolvidos, a partir dos lugares sociais que ocupam, procuram ativamente orientar-se em relação aos significados postos em circulação, confrontando-os com os sentidos por eles elaborados em suas experiências. Dessa perspectiva, compreender é produzir réplicas. Assim, todas as ações humanas são polissêmicas têm múltiplos significados e sentidos - e tornam-se significativas nas relações intersubjetivas em que são produzidas e compartilhadas. Ou seja, os sentidos elaborados dependem das posições e dos modos de participação dos sujeitos nas relações sociais.

Dessa perspectiva semiótica, o foco que interessa à compreensão está nas relações sociais nas quais os indivíduos estão envolvidos e como, nessas relações, historicamente determinadas, eles afetam e são afetados pelos signos e sentidos produzidos, singularizando-os e singularizandose. A compreensão é então um processo que apreende a singularidade que é produzida nas relações sociais multideterminadas.

Os termos de nossa opção, assim definidos, remeteram-nos a uma abordagem histórica e semiótica do processo de formação, entretecendo seu caráter pedagógico, concernente ao nosso papel de formadoras, a estudos contemporâneos relacionados a teorias do conhecimento, teorias da filosofia da linguagem, da história cultural e das ciências da educação.

Comprometidas com uma visão histórica da realidade educativa, passamos a abordar o cotidiano escolar não como um produto - o que é; mas como um processo em realização - o que está sendo. Processo esse multideterminado e contraditório, passível de ser apreendido, descrito, 
vivido e compreendido na dinâmica relacional que se estabelece entre seus participantes.

Nossas escolhas na condução das disciplinas teórico-práticas foram sendo apuradas e consolidadas pela mediação das relações produzidas entre os professores e nossos alunos. Nesse sentido, cabe dizer que, ainda que a direção dada a essas disciplinas venha sendo por nós estabelecida, ela não é só nossa. Os sentidos e eventos singulares, produzidos entre os sujeitos com quem vimos trabalhando, são constitutivos dos procedimentos de aproximação do universo social da escola de que lançamos mão. Eles também participam da configuração de nossa metodologia de trabalho, assentada na inserção nas relações produzidas entre os sujeitos que fazem e vivem a escola, no registro sistemático e na análise dessas relações em suas condições históricas de produção.

\section{Referências Bibliográficas}

AMADO, J. O grande mentiroso: tradição, veracidade e imaginação em História Oral. História, São Paulo, v. 14, p. 125-136, 1995.

AMORIM, M. O pesquisador e sen outro: Bakhtin nas Ciências Humanas. São Paulo: Musa Editora, 2001.

AUGÉ, M. Não lugares: introdução a uma antropologia da supermodernidade. Campinas: Papirus, 1994.

BAKHTIN, M. Marxismo e Filosofia da Linguagem. São Paulo: Hucitec, 1986.

BOURDIEU, P. (Org.). A miséria do mundo. Petrópolis: Vozes, 1999.

BRZEZINSKI, I.; GARRIDO, E. Análise dos trabalhos do GT Formação de Professores: o que revelam as pesquisas do período 1992-1998. Revista Brasileira de Educação, Campinas, n. 18, p. 82-100, set./out./nov./dez. 2001.

CERTEAU, M. A invenção do cotidiano: artes de fazer. Petrópolis: Vozes, 1994. A escrita da História. 2. ed. Rio de Janeiro: Forense Universitária, 2002.

CHARTIER, Anne Marie; JACQUET-FRANCILLON, F. Editorial. Recherche et Formation, Paris, n. 27, p. 5-14, 1998.

COMÊNIUS, J. Amós. A didática magna. Tratado da arte universal de ensinar tudo a todos. Lisboa: Fundação Calouste Gulbenkian, 1985.

DEJOURS, C. O fator bumano. Rio de Janeiro: Editora FGV, 1999.

DETIENNE, M.; VERNANT, J. P. Lês ruses de l'intellligence: la métis chez les grecs. Paris: Flammarion, 1974.

GINZBURG, C. Mitos, emblemas, sinais: morfologia e história. São Paulo: Companhia das Letras, 1989. 
HÉBRARD, J. O objetivo da escola é a cultura, não a vida mesma. Presença Pedagógica, Belo Horizonte, v. 6, n. 33, p. 5-17, maio/jun. 2000.

LINS, C. O documentário de Eduardo Coutinho: televisão, cinema e vídeo. Rio de Janeiro: Jorge Zahar, 2004.

OLIVEIRA, R. C. de. Olhar, owvir, escrever. Campinas: IFCH/UNICAMP, 1994. PORTELLI, A. Tentando aprender um pouquinho: algumas reflexões sobre a ética na História Oral. Projeto História, São Paulo, n. 15, p. 13-49, abr. 1997.

VYGOTSKY, L. Formaşão social da mente. São Paulo: Martins Fontes, 1984.

Pensamento e linguagem. São Paulo: Martins Fontes, 1987.

Recebido em: 03/03/2006

Aprovado em: 19/07/2006 